\title{
PRÁTICAS DE RESISTÊNCIA DE TERRA E MAR: PARENTESCO E MODOS DE EXISTIR NA VILA DO ESTEVÃO, CEARÁ, BRASIL \\ LAND AND SEA RESISTANCE PRACTICES: KINSHIP AND MODES OF EXISTENCE IN VILA DO ESTEVÃO, CEARÁ, BRASIL
}

\author{
Ana Luísa Nobre \\ lisboanobre@gmail.com \\ Mestre em Antropologia pela Universidade Federal de Sergipe (UFS). Professora voluntária da Universidade \\ Federal de Sergipe (UFS). Pesquisadora colaboradora do Grupo de Estudos Culturais, Identidades e \\ Relações Interétnicas (GERTS).
}

\section{RESUMO}

Os conflitos territoriais de terra e mar e as constantes investidas fundiárias nos territórios costeiros são uma realidade imediata para os povos do mar. Nesse contexto, destacamse projetos privados e políticas públicas para o turismo; para novas fontes energéticas, como as eólicas; e para novos campos produtivos, como a criação de camarão e o prevalecimento das tecnologias industriais de pesca sobre as artesanais. A experiência da Vila do Estevão - uma "comunidade" de pescadores localizada na praia de Canoa Quebrada, município de Aracati, litoral leste do estado do Ceará - apresentada neste artigo busca contribuições para o campo de questões sobre as práticas de resistência das chamadas comunidades tradicionais, sobre a invenção do cotidiano e a construção de respostas locais. O registro dessa experiência versa em torno de dois temas centrais que discutem formas situacionais de práticas e relações nativas: modos locais de fazer parentesco e modos de existir.

Palavras-chave: Práticas de resistência. Populações costeiras. Parentesco.

\begin{abstract}
Land and sea territorial conflicts and constant speculative approaches on coastal territories are an immediate reality for the 'sea people'. In this context, private projects and public policies for touristic purposes, as well as projects for alternative energy sources such as wind farms, and for new production fields such as shrimp farms and the prevailing industrial fishing technology over artisanal fisheries have significant importance. The experience of Vila do Estevão - a fishermen's 'community' settled in Canoa Quebrada beach, Aracati, east coast of the Ceará state, Brazil - shown is this article searches for contributions for the questions regarding resistance practices of the so-called traditional communities, the invention of quotidian and the construction of local responses. The records of this experience are developed around two central themes that discuss situational forms of native practices and relations: local ways of kinship and forms of existence.
\end{abstract}

Keywords: Resistance practices. Coastal populations. Kinship. 


\section{INTRODUÇÃO}

As populações costeiras do Nordeste têm vivido, desde a década de 1970, a invenção dos territórios praieiros como locais de lazer, contemplação e passagem (DANTAS, 2011; KNOX, 2009). Além disso, a criação de novos projetos energéticos, como o de energia eólica, o interesse da atividade turística pelos territórios ocupados por populações locais, as parcerias entre o Estado e empresas nacionais e transnacionais a fim de fazer uso dos recursos costeiros, a pesca em grande escala e o cultivo de camarão em cativeiro (carcinicultura) trazem novos atores sociais e diferentes concepções e apropriações para as praias. $\mathrm{O}$ contexto dos conflitos de terra e mar, que pauta a inseguridade territorial das populações costeiras e dispara disputas simbólicas, sociais, políticas e ambientais, também tem chamado atenção de instituições, pesquisadores e sociedade civil para os povos do mar e suas questões.

Muitos desses conflitos começam quando grupos econômicos, mobilizados por interesses em projetos privados, reivindicam a posse fundiária desses territórios. A disputa se acirra quando o Estado enxerga no turismo importante força econômica de desenvolvimento e começa a implementação de políticas públicas específicas, a exemplo do Programa de Desenvolvimento do Turismo em Zona Prioritária do Litoral do Ceará (Prodeturis) em 1989 e do Programa de Ação para o Desenvolvimento do Turismo no Nordeste (Prodetur/NE) no começo da década de 1990, do qual deriva o Prodetur/CE. Se, por um lado, esse contexto traz uma realidade imediata partilhada por muitas populações costeiras, por outro, serve como mote para que elas se pensem coletivamente a partir de suas identificações, organizem-se politicamente e criem estratégias de inserção em políticas territoriais.

A experiência da Vila do Estevão, que apresentarei neste artigo, é um convite para pensar sobre as estratégias e práticas de resistência dessas "comunidades", sobre como nesse contexto imediato o cotidiano se inventa, respostas locais são gestadas e a modernidade se indigeniza (SAHLINS, 1997a). A abordagem aqui proposta busca olhar mais atento para a intencionalidade histórica que conformam as práticas locais. Se há evidente contexto de homogeneização e aproximação com as semelhanças culturais da globalização - fonte de interesse de várias publicações no campo das ciências sociais -, há também modos locais de diferenciação e distinção que precisam de registros antropológicos na literatura sobre essas populações.

Adentramos, assim, o cenário de nossa experiência etnográfica: a Vila do Estevão, uma "comunidade" pesqueira localizada na turística praia de Canoa Quebrada, município de Aracati, litoral leste do estado do Ceará, Brasil. Canoa Quebrada está distante cento e setenta quilômetros da capital cearense e doze quilômetros da cidade de Aracati, sede do município do qual faz parte. Oficialmente considerada bairro de "Canoa", como se torna conhecida - que é um destino turístico conhecido internacionalmente desde a década de 1970 -, a Vila do Estevão, no entanto, reivindica um estatuto de tradicionalidade, demarcando diferença diante do restante do lugar.

Distando duzentos metros do centro de Canoa Quebrada a oeste, a vila é formada por 70 famílias com 313 moradores (TAKAHASHI, 2016) e foi fundada em 1932. Os pescadores passam um semestre do ano voltados, especialmente, para a pesca da lagosta e outro semestre, na época do defeso - em que a pesca é temporariamente suspensa para garantir a reprodução da espécie -, pescando de linha, além de, em época de "alta estação" turística, realizarem passeios turísticos em suas jangadas.

O "Estevão" ou "Esteves" é visto, tanto pelos olhares de fora quanto pelos de dentro, como lugar originário de toda Canoa Quebrada, onde é ainda 
possível ter acesso a um tempo do começo. Essa longevidade é associada a um modo de vida pesqueiro e "tradicional", a uma relação ambientalmente positiva com o território e marcada por laços de parentesco compartilhados pela descendência comum de Estevão, fundador da vila. O ponto marcante dessa diferença, em termos territoriais, está no fato de os moradores do Estevão terem conseguido, após um processo de negociações e disputas conhecido como "a luta pela terra", o título de Domínio no nome da AMECQ, que regulamenta seus usos e ocupações.

Desde 1960, "Canoa" inaugura um processo de chegada de estrangeiros e turistas na praia. Num primeiro momento, a praia era compreendida como lugar de livre acesso aos recursos marítimos e à terra, conforme as narrativas dos moradores sobre o lugar. Depois, grupos de elite começaram a frequentar o espaço sazonalmente, evento recorrente em muitas zonas litorâneas, e no fim da década de 1960 um filme francês chamado Le Grabuge é gravado ali. Muitas vezes, ouvi os moradores - assim como li nos materiais das agências de turismo e em sites na internet - referenciando a divulgação do filme como responsável por revelar Canoa Quebrada e lançá-la para o mundo. Ainda segundo as narrativas, é em 1976 que os primeiros viajantes - andarilhos, de maioria estrangeira, especialmente europeia, que estavam em busca de uma nova forma de viver e se relacionar, influenciados pelo movimento de contracultura hippie dos anos 1960 nos Estados Unidos - chegam. Dessa forma, Canoa Quebrada foi ganhando fama nacional e internacional e, posteriormente, criou-se um fluxo mobilizado por interesses diversos, especialmente depois da construção de uma via asfaltada que dá acesso à praia em 1980. Em 1978, "Canoa" vive a primeira investida fundiária. Nesse evento, a área da Vila do Estevão estava fora do perímetro de especulação. A segunda investida fundiária acontece anos depois, em 1986, dessa vez na Vila do Estevão Nessa ocasião um empresário, proprietário da Machado Correia Empreendimentos Imobiliários Ltda., o chamado "dono da terra", pretendia construir um resort "ecológico" chamado Baía de São Pedro em cima da área de moradia da Vila, objetivo que pretendia atingir pedindo judicialmente a reintegração de posse devido à invasão de terras particulares.

Com os moradores mais inteirados dos interesses de cunho privado pela terra desde o evento de sete anos antes, foi construída a possibilidade de ação. O processo judicial resultou na desapropriação do reconhecido proprietário por utilidade pública, em 1986. Em 1997, a Área de Proteção Ambiental de Canoa Quebrada (APA-CQ) foi criada, compreendendo todo o território da praia. No ano seguinte, a Área de Relevante Interesse Ecológico do Estevão (ARIE-Estevão) é criada exclusivamente no perímetro da Vila. Ambas as unidades de conservação (UC) são municipais. No entanto, de acordo com o Sistema Nacional de Unidades de Conservação da Natureza (Snuc), a APA é uma UC que conforma uma população já consolidada com diversas atividades existentes no seu interior e compreende uma grande área, enquanto a ARIE conforma pequena extensão, com nenhuma ou pouca ocupação humana (BRASIL, 2000), sendo criada primeiramente por causa de suas características naturais extraordinárias e por servir de abrigo a exemplares raros da biota regional (ARACATI, 1998). AARIE-Estevão é criada com a finalidade de proteger os "ecossistemas locais", as "belezas cênicas e paisagens notáveis" e, por fim, a "unidade social da comunidade do Estevão” (Ibidem, p. 2).

Em 2006, um órgão estadual, o Instituto de Desenvolvimento Agrário do Ceará (Idace), autarquia especial estadual responsável por executar as políticas públicas agrárias, adentrou a questão fundiária da Vila emitindo o Título de Domínio $\mathrm{n}^{\circ}$ 6.470/2006 que conferiu a propriedade da área de moradia à AMECQ. Estamos falando, portanto, de existir numa mesma zona espacial parte de Canoa Quebrada territorialmente assegurada, que é a Vila do Estevão, e o restante da praia não. Nesse contexto, a associação criou as primeiras normas de uso e ocupação do solo, uma vez que precisa garantir, continuamente, boa gestão 
territorial perante o Idace. A especulação fundiária vinha não só de fora, mas também dos moradores do centro, que vendiam suas terras a baixo custo e buscavam outros espaços para cercar e vender novamente, além dos moradores da Vila que não legitimavam as regras de uso impostas pelo Idace, endossando práticas que se tornaram ilegais. Enquanto em "Canoa" a terra se insere numa lógica de mercado, na Vila a terra adentra a lógica protecionista das APP, sendo proibitivo qualquer desmembramento ou venda (ASSOCIAÇÃO DOS MORADORES DO ESTEVÃO DE CANOA QUEBRADA, 2005; CEARÁ, 2006), só sendo permitido o uso do território exclusivamente para morar.

Há um discurso muito presente que destaca a dicotomia entre centro e vila. Existe uma diferenciação e estigmas em ser de um ou doutro lugar. Os moradores do centro são geralmente vistos pelos do Estevão como os que aceitaram viver em conformidade com o desenvolvimento do turismo na praia e com as transformações que essa atividade provocou de forma física, social, cultural e econômica, com ênfase nos inúmeros problemas oriundos dela. $\mathrm{Na}$ vila, é comum ouvir referências dos moradores a um "centrinho moderno", "urbano", que remete à ideia de um morador de Canoa considerado indiferente, resignado, vendido. Os moradores do Estevão se veem como os que recusam e resistem, existe um orgulho muito grande em torno da "luta" e conquista da terra em 1986. No centro, por sua vez, há discurso de civilidade. São modernos, os que não ficaram parados no tempo, que vêm se desenvolvendo, progredindo, usufruindo do fluxo de turistas na praia. É lá onde circulam grandes quantias, onde se ganha dinheiro, onde se apresentam possibilidades.

A soma de todos esses elementos e conflitos compõe a atual praia de Canoa Quebrada que afetou tantos moradores, turistas e viajantes. O centro de "Canoa" vem passando por um processo de transformação contínuo. Canoa Quebrada assume novas formas: do forró ao reggae, da Rua Dragão do Mar à Broadway, da areia ao calçamento, dos ofícios ditos tradicionais aos de alta temporada turística. Muitos moradores acham que com tantas mudanças, a "magia" também se perdeu. A Vila do Estevão é o lugar onde muitos acreditam ainda ser possível acessar um "antigamente" e onde é possível sentir a tão conhecida "magia" de Canoa Quebrada.

O processo de litoralização (DANTAS, 2002) disparado a partir da década de 1980 no Nordeste, com especial alcance no Ceará, tem a construção da imagem de Fortaleza enquanto "Cidade do Sol" como paradigmática, mas pode ser visualizada também através do caso de Canoa Quebrada. A cidade de Aracati desempenhou papel fundamental na época da colonização por desenvolver atividades econômicas importantes - a produção de itens para o mercado regional, como a carne seca - e devido à sua localização estratégica. A cidade localiza-se na foz do Rio Jaguaribe, que tem quinhentos e sessenta quilômetros e atravessa quase metade da extensão territorial do estado (GIRÃO, 1986), e também está a doze quilômetros do mar, facilitando a venda dessa carne para outras localidades, assim como a comunicação com outros territórios. Desse modo, torna-se uma das cidades mais importantes da capitania do Ceará (POMPEU SOBRINHO, 1937), especialmente pelo controle que exercia sob um dos principais portos do litoral do estado (DANTAS, 2011).

Até o fim da década de 1980, a cidade de Aracati esteve associada à imagem de uma localidade sertaneja, interiorana, relacionada à criação do gado e ao desenvolvimento da agricultura. É quando a cidade adentra a política de consolidação da atividade turística no Nordeste a partir da valorização das zonas da praia. Desse modo, as praias de Quixaba, Canoa Quebrada, Cumbe e Majorlândia são incorporadas como distritos sob o domínio de Aracati, possibilitando a construção de uma imagem turística fomentada tanto pela sua arquitetura colonial que remete à relação com o passado sertanejo, inclusive tombada pelo Instituto do Patrimônio Histórico e Artístico Nacional (Iphan) em 2005, quanto 
pela evocação de uma relação com o mar, a partir de novas práticas marítimas associadas ao veraneio e turismo (Idem, 2011) conjugadas às anteriores (especialmente à pesca praticada pelas populações locais).

Emerge assim uma maritimidade (Ibidem) a partir dos veraneios das elites locais que enxergam as zonas de praia como locais de lazer, sem perder de vista os laços culturais com o sertão, incorporada pelo marketing turístico que veicula a imagem de Canoa Quebrada mundo afora. Nesse sentido, são produzidas novas territorialidades para poder conformar essa nova demanda, a partir de um processo de urbanização que focalizou o centro. Destacam-se a construção de uma estrada estadual asfaltada que interliga Aracati a seus territórios praieiros, a CE 040, que desemboca na avenida principal de Canoa Quebrada também asfaltada, preenchida de estabelecimentos comerciais, agências de turismo e restaurantes e de uma rede bem estruturada de hotéis, pousadas e barracas de praia.

Assim, a paisagem vai sendo transformada, as populações que moravam nesses locais sendo distanciadas e a vila emerge como lugar do antes por causa das poucas intervenções arquitetônicas em seu território se comparadas às do centro: há um areal que se mantém, as casas são identificadas como modo típico e tradicional de morar, o lugar é exclusivamente de moradores, a saber, uma "aldeia" ou "vila" de pescadores, sem estabelecimentos ou empreendimentos comerciais, os postes são poucos, a fiação é enterrada na maior parte do lugar... Se por um lado, isso é resultado da imposição de normas preservacionistas de uso e ocupação do solo, por outro, o turismo usufrui da possibilidade de explorar a vila como produto turístico.

Podem ser identificados diversos fluxos e movimentos criativos e inventivos na Vila, motivados por desejos múltiplos diante das questões apresentadas, sejam eles de resistência ou não. Apesar das várias mobilizações, existem práticas que tornam possível a manutenção de características tão quistas como a relação com o mar, a pesca artesanal, os valores praianos dos jangadeiros como o silêncio, o mistério, a constituição física do território. Existe uma crítica localmente produzida, um discurso hegemônico, coletivo e coercitivo orientando as formas de viver e caracterizando enfrentamento aos interesses advindos das práticas econômicas no lugar. No restante de Canoa Quebrada, os movimentos de resistência costumam ser mais contra hegemônicos e resultam de uma busca mais pessoal ou feita em pequenos grupos do que comunitária.

O registro dessa experiência versará em torno de dois temas centrais que discutem formas situacionais de práticas e relações tradicionais: (i) modos locais de fazer parentesco e (ii) modos de existir.

\section{MODOS LOCAIS DE FAZER PARENTESCO}

No contexto da utilização mercantil das terras praianas (RODRIGUES, 2010), a AMECQ definiu estatutariamente como critério para ser morador da vila ter nascido em terras estevenses e/ou ali viver vinte anos ininterruptos e com moradia fixa (ASSOCIAÇÃO DOS MORADORES DO ESTEVÃO DE CANOA QUEBRADA, 2005). O morador que cercar algum terreno ilegalmente, vendê-lo ou trocá-lo poderá ser punido com a perda dos seus direitos de ocupação e dos seus filhos. Durante minha trajetória de pesquisa na Vila, pude perceber que a via da descendência se apresentava como forma muito importante de pertença familiar, prevendo o direito ao uso do território. Notando a polissemia dos sentidos de família, percebi que existem outros modos de fazer parentesco que não passam necessariamente por descendência informada pela consanguinidade. $\mathrm{O}$ "sangue" não se revelou como princípio fundamental e único que determinasse a participação de um sujeito na 
vida do grupo em questão. No caso da Vila, muitas vezes esses princípios aparecem sobrepostos ao laço sanguíneo, coexistindo numa mesma relação.

Essas conexões são observáveis, por exemplo, entre os homens que dividem as jangadas de pesca por muitos anos. Na pescaria "de dormida", um interlocutor observa que praticamente não se conversa. Os homens precisam estar atentos aos sinais da natureza: as estrelas, as nuvens, o mar, o vento. Diz ele que "também são amigos desde a infância, muitas vezes primos, irmãos". Por isso até se é capaz de adivinhar "no que o outro não está pensando". Falar é ato secundário, porque a conexão substancial entre eles (SAHLINS, 2011), sendo construída "desde a infância", fala muito mais: eles conhecem o jeito de se movimentar uns dos outros, compartilham do conhecimento do ofício de trabalhar no "molhado". Essa fala revela, além do compartilhamento de sensações, sentimentos e substâncias, a importância de um tempo estendido (Ibidem) para a criação e manutenção das conexões parentais em que a temporalidade vigente é a da implicação recíproca das existências. O critério estabelecido de viver por vinte anos ininterruptamente na vila para adquirir o direito de morador, por exemplo, vem do reconhecimento da importância dessa temporalidade.

Esses vínculos também estão presentes no universo mais estritamente feminino, o gênero terrestre da vila, posto que "Homens e mulheres nas suas atividades respectivas, tradicionais, seculares, cujo aprendizado se fazia de geração em geração. Ofício herdado. Homens e mulheres. Pescadores e labirinteiras, eles no mar, elas na terra. Cada dia, eles partiam" (KUNZ apud MELANCIA, 2005, p. 15). Na copresença e interdependência (SAHLINS, 2011) geradas por estarem na terra, "no seco", com ou sem o marido, o tio, o pai que estão embarcados na execução de seu ofício e por assumirem a responsabilidade da criação dos filhos, no acompanhamento das questões cotidianas relacionadas a casa e no engajamento com as questões territoriais se criam também relações familiares: a tia, a madrinha-parteira, a comadre, os irmãos de criação, os primos. Segundo Carsten (1997, p. 128), em sua pesquisa com pescadores na Malásia, o universo da casa é um dos "sítios de produção de parentesco", tendo as mulheres papel central nesse processo.

Os exemplos acima citados revelam modos locais de fazer parentesco que transcendem a gramática do "sangue" e estão sendo investigados em uma pesquisa em curso. Para este artigo, gostaria de apresentar um aspecto que se destaca quando discutimos parentesco enquanto prática de resistência em um território em conflito. Em conflito porque, por mais que os estevenses tenham direito de uso assegurado pelo Governo do Estado do Ceará até 2016, os interesses pelo território não cessaram e as disputas entre populações locais, Estado e iniciativas privadas seguem.

Falo do universo da AMECQ. Na Vila, em vez de a terra adquirir valor de troca como no centro de Canoa Quebrada - e justamente como tentativa de evitar isso - ela se tornou tabu (RODRIGUES, 2010) quando a associação proibiu a sua venda. Existindo poucos troncos familiares distintos na Vila, a maioria dos moradores consideram-se parentes, de formas diferenciadas, compondo "a família Estevão". Desse modo, os sujeitos que ocupam cargos institucionais na associação precisam fiscalizar, impedir e punir os que fazem usos irregulares do território, muitas vezes entre os próprios familiares. Essa obrigação vai de encontro à expectativa de encontrar solidariedade e apoio entre familiares e ao valor local tão quisto da "união". Nas palavras de uma interlocutora, filha de uma importante liderança muito engajada na AMECQ, que já ocupou vários cargos institucionais: "para levar isso [o estatuto] a sério, tem que ser ruim, se for bom, não segue o estatuto não".

É porque as relações parentais criam sentimento de que o que acontece na vida de um parente é sentido pelos outros que esse conflito existe. Se um parente é punido, isso terá implicação na vida de outrem. Por esse motivo 
se considera que é preciso "ser ruim", "de pulso firme" ao se colocar de lado a obrigação parental de "ser bom", "sangue bom", em nome do interesse coletivo e em respeito à memória dos antepassados que são, em última instância, importantes deveres de parentesco também.

Nota-se a existência de conflito entre duas coletividades - a dos grupos familiares e a do coletivo "Vila do Estevão" ligado à AMECQ - por apresentarem ordens de relações sociais, moralidades e gramáticas sociais distintas, que vão de encontro e rivalizam. Essa prática é de extrema importância na disputa pelo território e adquire forma situacional. Se não houvessem conflitos territoriais, a disputa entre essas ordens talvez não precisasse existir, mas, nesse contexto, ela mantém a coerência e o argumento da associação, trazendo legitimidade à sua gestão.

Sejam consanguíneas ou não, as relações de parentesco produzidas na Vila seguem um critério fundamental: a consideração. Ela está presente na obrigação moral de considerar os procriadores. Está presente na possibilidade de reconhecer, legitimar conexões entre pessoas que se tornaram parentes processualmente. Está presente nas categorias locais de "nativo" e "morador". Está presente na definição de "vagabundo". Está presente, em suma, na necessidade de diferenciar e localizar socialmente os sujeitos em relação a si, numa espécie de mapeamento (TEIXEIRA, 2014) no qual é identificada a intenção deles com a "família Estevão", com quem afirmam proximidades e distanciamentos, como se colocam em relação à questão territorial e de sua gestão no contexto em que a terra pode ser compreendida como dádiva recebida por ser parente. Embora a terra não possa ser transmitida, o direito de ocupá-la sim.

A categoria local "nativo" refere-se ao sujeito que tem vínculo com o território, ou seja, que tem o Estevão como sua terra natal, é originário daquele lugar. Já o "morador" é considerado aquele que tem vínculo com o território, porque ali vive, mas remete também à outra dimensão que é a de estar implicado moralmente com o lugar, com as pessoas, com o modo de vida. Dito de outro modo, não basta ser "nativo", é preciso ser "morador" para ser reconhecido, considerado. Já o "vagabundo" é um sujeito liminar que está entre o dentro e o fora, o nós e os outros, a família e os estranhos. Ele tem uma trajetória itinerante, que encarna o conflito e ruído da vida social na vila, sendo o parente sem consideração, por ser mobilizado por motivações contra hegemônicas que vão de encontro aos interesses da associação: ele é o que pretende vender ou trocar as terras que ocupa, faz construções irregulares, defende o direito de construir empreendimentos no local, não reconhece a legitimidade da associação enquanto gestora.

A percepção do "vagabundo", acerca da presença desse outro - que pode ser o turista, o bugueiro ou alguém de fora - é a compreensão de que ele traz a possibilidade de transformação diante de uma gestão que incorpora lógica de disciplinarização e racionalização do uso territorial. O encontro com a diferença do outro tonaliza a cena com as sombras oriundas do desejo, que pode ser mobilizado pela vontade de ascensão, seja ela econômica, social ou profissional. Pode ser também o desejo de viver o novo, uma sede de conhecer, aprender uma nova língua, viajar para outras cidades ou até países, ter outras vivências que não seriam possíveis no contexto local. Pode, ainda, ser o desejo da liberdade de vender o terreno, de construir a casa como quiser, de construir pousadas ou restaurantes, de inaugurar fluxos constantes desses outros dentro da vila. Esses desejos estão agenciados de formas múltiplas em cada compreensão intersubjetiva das diversas cenas no cotidiano da vila.

Em muitos casos, o "vagabundo" também pode ser alguém de fora, que foge às conexões parentais e ao âmbito familiar, mas que revela o lugar que o outro pode assumir na vila no mesmo processo de mapeamento que se faz internamente. $\mathrm{O}$ "vagabundo" de fora nunca é um parente em potencial - sem consideração não há parentesco - e sua identificação também é uma estratégia importante de resistência. 
O bugueiro, por exemplo, é ator social com o qual existe um conflito histórico e que encarna a figura do "vagabundo" de fora. O conflito entre bugueiros e estevenses é baseado na disputa pelo tráfego no território e é atravessado por um jogo de forças que envolve uma disputa simbólica sobre a presença de dois agentes externos: um é o próprio bugueiro, homem nascido em Canoa Quebrada, que se insere no turismo através da realização dos passeios pelas dunas e falésias; o segundo é quem ele transporta, o turista. Em outras palavras, a disputa aqui é a presença desse "nativo" considerado "corrompido" e do turista contra o "nativo" que resiste e recusa, que entende sua trajetória como buscando fortalecer o "modo de vida tradicional" no e do Estevão.

O bugueiro reivindica o direito de incluir na sua rota a passagem pela Vila do Estevão. Ele, com seu buggy, elemento de modernidade considerado destruidor - destrói a falésia, levanta areia, produz ruído no tão quisto silêncio da vila, perturba o sossego dos pedestres e a livre brincadeira das crianças - transporta e aproxima o turista à "comunidade mais tradicional de Canoa Quebrada", na qual se acessa um tempo do começo da praia, antes da chegada dele próprio (o turista). A resistência a esse trânsito de presenças de outros orienta práticas locais como a construção de barricadas e colocação de madeiras para impedir a passagem dos buggys, e acaloradas discussões entre bugueiros e moradores. Desses e outros encontros conflituosos, surgiram estigmas que acompanham o estevense, não raramente chamados de "índios", "primitivos", "violentos" e "não civilizados".

Dessa maneira, o fluxo de presenças na vila também é observado e acompanhado e associa-se à produção local do parentesco diante da necessidade de assegurar o território. Assim, os estevenses produzem uma síntese sobre quem tem direito de morar, transitar e estar no seu lugar. Essas práticas adquirem formas próprias em contextos singulares, ressignificando relações antigas, mostrando que os fluxos globais, ao se infletirem localmente, diversificam-se de acordo com esquemas culturais particulares (SAHLINS, 1997b).

\section{MODOS DE EXISTIR}

Seguindo o fluxo do fio analítico sobre práticas de resistência, gostaria de destacar três que revelam modos de existir que surgem como elementos de identificação nos discursos identitários do estevense: a vivência da calmaria e o silêncio, da alegria e da guerra. Elas produzem múltiplos devires, no sentido proposto por Félix Guattari (1981), que escapam ao controle e mobilizam desejos. Devir entendido como:

o agenciamento coletivo do socius que não procura mais fazer com que as pessoas entrem nos quadros preestabelecidos, para adaptá-los a finalidades universais e eternas, mas sim que aceita o caráter finito e delimitado historicamente dos empreendimentos humanos. É sob essa condição que as singularidades dos desejos serão respeitadas (...) Construir sua própria vida, construir algo de vivo, não somente com os próximos, mas consigo mesmo, para modificar, por exemplo, sua relação com o corpo, com a percepção das coisas. (GUATTARI, 1981, p. 66-67)

A primeira, a calmaria e o silêncio introspectivo, traz uma relação próxima com o pescador quando vai para o mar. Esse devir pescador e a transmissão de seus ofícios e ensinamentos remete à ideia de uma introspecção forte, escuta e observação e uma relação próxima com os ciclos da natureza. Esse silêncio imenso surge como uma das marcas distintivas da vila: enfadada pelo sol de um dia de pesca, pela necessidade de ler o céu e as estrelas, prever temporais e perceber o mar nas suas "voltas", "beiços" e "peraus", como os pescadores nomeiam as localidades de dentro do oceano. 
A alegria evoca um estevense como pessoa festiva e extrovertida, que gosta de fazer piada, contar "causos", dançar e rir, tem a fala alta, o gesto expansivo, a língua afiada e gargalhadas enormes. O calendário festivo é movimentado, as datas comemoradas como a dança do coco, o forró, o tradicional bloco de carnaval Moqueca de Canoa, a quadrilha de São João, a queima do Judas e a Regata de Jangada do Estevão. Contam os moradores que a dança do coco foi aprendida em Majorlândia, "comunidade" pesqueira vizinha e surgiu como necessidade de tornar o trabalho, que era muito árduo e debaixo de muito sol, mais alegre. Transportando "quengas" de coco em uma égua, os cascos do animal na areia produziam um ritmo que é a base para a musicalidade e a dança, que imita com as pisadas a passada do bicho.

Um devir guerreiro traz a imagem de um estevense ruidoso, aguerrido, bélico, intempestivo, impetuoso e disposto para a "luta". A ideia de enfrentamento e resistência conforma um campo discursivo acionado nos contextos de posicionamento em relação ao Estado, ao turismo, à especulação imobiliária, às "lutas" da associação e ao enfrentamento cotidiano do mar. Investidos de autoimagem fortalecida por uma "luta pela terra" vitoriosa, na qual as populações costeiras costumam sair perdedoras, os estevenses constroem esse devir guerreiro, a partir de um imaginário de um jeito de ser produzido coletivamente, que faz que sejam possíveis práticas cotidianas de resistência, modos de operação, esquemas de ação e astúcia (CERTEAU, 1998).

Os conflitos existentes entre "vagabundos" e moradores sempre passam pela reunião da associação. Por mais que o "vagabundo" não esteja presente, a existência do conflito é sempre comunicada aos outros moradores, e lá, outras opiniões são dadas e o que vai ser feito em relação ao caso é encaminhado. Ali se cria um sentimento coletivo em relação ao outro "vagabundo": "egoísta", "perturbador", "mesquinho" e também perigoso, no sentido de ameaçar as práticas de resistência. A diferença em relação ao outro de fora é que se tem uma expectativa de que todos que são da vila assumam e cuidem dessas mesmas práticas. Há uma coercitividade grande nesse sentido. O rancor gerado pela frustração do código de conduta também vem muito no sentido do desrespeito pelas pessoas que vêm garantindo a continuidade da vila como ela é e pela memória das lutas e dos sofrimentos passados por elas: esses valores compõe um sistema de atitudes e expectativas entre parentes.

Muitos desses encaminhamentos sobre usos irregulares resultam em ações diretas: reúnem-se as famílias, adultos, jovens, grávidas, crianças e mulheres, levando paus, pedras, boca-de-lobo e o que mais for preciso para derrubar e descercar, caso haja resistência por parte de quem está construindo irregularmente. É uma das ações diretas mais simbólicas, juntamente com a construção de barricadas para impedir o trânsito de carros pela falésia, que configuram um conjunto de maneiras de pensar investidas nas maneiras de agir.

Devir pescador, devir festivo e devir guerreiro são multiplicidades de práticas que fazem o cotidiano do Estevão. São linhas de fuga que, embora reúnam em si modos "antigos" de existir, reinventam-se cotidianamente e fazem a "comunidade" escapar às "engrenagens essenciais para o bom funcionamento do sistema de autossujeição dos indivíduos à produção" (GUATTARI, 1981, p. 13). As práticas que configuram esses devires se enredam na vila segundo duas lógicas de ação diferentes: por meio de estratégias e/ou táticas, que inventam o cotidiano, no sentido proposto por Michel de Certeau (1998). Ambas podem ser compreendidas como meios de apropriação e indicadores de criatividade dentro de um contexto de dominação imediatamente inevitável.

Algumas dessas práticas são mobilizadas pela associação, por meio de seu estatuto, de suas normas, de suas atividades, da politização das ações, da tentativa de sobreposição do sistema de atitudes institucionais sobre 
algumas obrigações de parentesco. A elas podemos chamar de estratégias, tendo em vista que possuem um caráter institucional, buscam um lugar próprio e têm a finalidade de reverter à ordem posta. Sistematizam o pensamento e produzem um discurso.

As táticas não. Elas acontecem em um nível microscópico, dos detalhes, das ocasiões, dos fragmentos e das interrupções. Pensando em relação ao contexto do turismo em Canoa Quebrada, as táticas de resistência são marcadas pelos devires que encontramos no cotidiano do Estevão, onde a tendência é a adesão às prerrogativas capitalistas do modelo turístico: a transformação da terra e do peixe em mercadoria, o prevalecimento das tecnologias modernas de pesca sobre as artesanais, a criação de grandes empreendimentos para receber os turistas ou que ofereçam suporte energético (eólicas), produtivo (carcinicultura) e o lançamento de cada vez mais novos produtos turísticos.

\section{CONSIDERAÇÕES FINAIS}

Devir e táticas são modos incapturáveis, não se estocam, não se acumulam, não se conservam e, por isso, não criam formas, estruturas nem repertórios. Com o que foi apresentado, busquei apenas identificar conjuntos de práticas de resistência em constante câmbio e que coabitam com as do campo de dominação. $\mathrm{Na}$ tentativa de perpetuá-la sobre as populações e localidades que se tornam destinos turísticos, os grupos empresariais e estatais ligados a essa importante força econômica, por saberem que podem ser superados, buscam reinventar a cada dia novas práticas: elas podem ser acintosas, claras, agressivas, invasivas, mas também sutis, camufladas, sedutoras. Para fazer frente a elas, os estevenses se organizam, criam instituições, buscam reconhecimento, produzem discursos identitários de diferenciação. Mas, com a mesma determinação, também controlam seus membros por meio de códigos de conduta, normas e regras que se infletem nas relações de parentesco e em todas as relações comunitárias. Alguns aderem às normas, outros se desviam delas.

Todos, porém, entre estratégias e táticas, buscam meios de subverter a ordem dominante e se posicionar diante dela. Ninguém é um "consumidor" passivo que apenas reproduz o que lhe é transmitido ou imposto, ou seja, ao fazer usos dos ensinamentos, das antigas aprendizagens ou mesmo dos modos consolidados de praticar o cotidiano (CERTEAU, 1998). As pessoas sempre e invariavelmente os recriam, os reinventam, saindo assim de um lugar de passividade e apatia. Assim, seja através de estratégias e/ou de táticas, os estevenses produzem inúmeras possibilidades de resistências diante da ordem posta e totalizante.

Existe esforço e mobilização constante dos estevenses em torno da reinvenção da vila por meio do intercâmbio com outras "comunidades" costeiras, da instrumentalização da "cultura" e da "história", da inserção numa lógica e linguagem do direito, da articulação político-institucional, da mobilização interna, da vigilância em relação à questão territorial, da administração ou (re) produção de conflitos.

\section{REFERÊNCIAS}

ARACATI (Cidade). Lei no 40, de 20 de março de 1998. Determina o limite da área de preservação ambiental e paisagística da zona costeira do município. Diário Oficial do Estado, Aracati, marco de 1998. 

BRADA. Reforma do estatuto da Associação dos Moradores do Estevão de Canoa Quebrada-AMECQ. Aracati, 2005.

BRASIL. Lei n. 9.985, de 18 de julho de 2000. Regulamenta o art. 225, § 1ํ, incisos I, II, III e VII da Constituição Federal, institui o Sistema Nacional de Unidades de Conservação da Natureza. Diário Oficial da União, Poder Executivo, Brasília, DF, 19 de julho de 2000. Disponível em: <http://bit.ly/lbPMrfW>. Acesso em: 6 nov. 2015.

CARSTEN, Janet. The heat of the hearth: the process of kinship in a Malay fishing community. Nova Iorque: Oxford University Press, 1997.

CEARÁ (Estado). Instituto de Desenvolvimento Agrário do Ceará. Título de domínio $n^{\circ}$ 6470, de 30 de novembro de 2006. Fortaleza, 2006.

CERTEAU, Michel de. A invenção do cotidiano: artes de fazer. v.1. ed. Petrópolis: Vozes, 1998.

CUNHA, Tânia Batista da; VIEIRA, Sarita Brazão. Entre o bordado e a renda: condições de trabalho e saúde das labirinteiras de Juarez Távora/Paraíba. Psicologia: ciência e profissão, Brasília, DF, v. 29, n. 2, p. 258-275, 2009. Disponível em $<$ https://goo.gl/GxAvCb>. Acesso em: 6 nov. 2015.

DANTAS, Eustógio Wanderley Correia. Construção da imagem turística de Fortaleza/Ceará. Mercator: Revista do Departamento de Geografia da UFC, v. 1, n. 1, p. 53-60, 2002.

. Mar à vista: estudo da maritimidade em Fortaleza. 2. ed. Fortaleza: Edições UFC, 2011.

GIRÃO, Raimundo. A marcha do povoamento do Vale do Jaguaribe (16001700). Fortaleza: Gráfica Editorial Cearense Ltda., 1986.

GUATTARI, Félix. Revolução molecular: pulsações políticas do desejo. 3. ed. São Paulo: Brasiliense, 1981.

KNOX, Winifred. Vivendo do mar: modos de vida e de pesca. Natal: EDUFRN, 2009.

MEIRELES, Antônio Jeovah de Andrade; QUEIROZ, Luciana de Souza. Certificação da carcinicultura no Brasil: o manto verde da destruição. Fortaleza: Instituto Terramar, 2011.

MELANCIA, Zé. Cordel - Zé Melancia. Fortaleza: Editora Hedra, 2005.

PEREIRA, Ana Luisa Lisboa Nobre. Peixe bom, sangue bom: uma etnografia das relações de parentesco no contexto da especulação da terra na vila do Estevam. 2013. 94 f. Monografia (Graduação em Ciências Sociais) - Centro de Humanidades, Departamento de Filosofia e Ciências Sociais, Universidade Federal do Ceará, Fortaleza, 2013.

POMPEU SOBRINHO, Thomaz. Povoamento do Nordeste brasileiro. Revista do Instituto do Ceará, Fortaleza, v. 51, p. 107-162, 1937.

RODRIGUES, Lea Carvalho. Turismo, empreendimentos imobiliários e populações tradicionais: conflitos e interesses em relação à propriedade da terra. Civitas, Porto Alegre, v. 10, n 3, p. 527-554, 2010. 
SAHLINS, Marshall. O "pessimismo sentimental" e a experiência etnográfica: porque a cultura não é um "objeto" em via de extinção. Parte I. Mana, Rio de Janeiro, v. 3, n. 1, p. 41-73, 1997 a.

O "pessimismo sentimental" e a experiência etnográfica: porque a cultura não é um "objeto" em via de extinção. Parte I. Mana, Rio de Janeiro, v. 3, n. 2, p. 103-150, 1997 b.

. What kinship is (part one). Journal of the Royal Anthropological Institute, Londres, v. 17, n. 1, p. 2-19, 2011.

SILVA, Vilma Célia Pereira da. Os danos ambientais causados pela implantação e operação do Parque Eólico Centraleólica Canoa Quebrada em dunas móveis na comunidade do Estevão, Canoa Quebrada, município de Aracati, Ceará. 2012. 31 p. Monografia (Graduação em Direito) - Universidade Potiguar, Mossoró, 2012.

TAKAHASHI, Saori. Estratégia da gestão turística de base comunitária em unidade de conservação: ÁRIE da Vila do Estevão, Aracati-Ceará. 2016. 158 f. Dissertação (Mestrado) - Programa de Pós-Graduação em Desenvolvimento e Meio Ambiente, Universidade Federal do Ceará, Fortaleza, 2016.

TEIXEIRA, Jorge Luan Rodrigues. Na terra dos outros: mobilidade, trabalho e parentesco entre os moradores do Sertão dos Inhamuns (CE). 2014. $234 \mathrm{f}$. Dissertação (Mestrado em Antropologia Social) - Programa de Pós-Graduação em Antropologia Social do Museu Nacional, Universidade Federal do Rio de Janeiro, Rio de Janeiro, 2014. 